\title{
Trends in cesarean delivery rates in primipara and the associated factors
}

\author{
Guoqiang Sun, Ying Lin, Honglian Lu, Wenjing He, Ruyan Li, Lijun Yang, Xian Liu, Hongyan Wang, \\ Xuewen Yang and Yao Cheng*
}

\begin{abstract}
Background: Few studies have focused on cesarean delivery (CD) trends among primipara under the one-child and the two-child policies. This study aimed to explore the trends in CD rates among primipara during 1995-2019 and the associated factors with CD risk.

Methods: This study obtained clinical data on primiparous mothers and newborns from 1995 to 2019 at a large tertiary hospital in Wuhan, China. Trends in CD rates were calculated using the joinpoint regression analysis. The Chi-square tests and log-binomial regression analyses were used to evaluate the associations between primary variables and CD risk.

Results: CD rates showed a significant upward trend with an average annual percentage change (APC) of 2.2\% (95\% Cl: 0.6, 3.8\%) during the study period. In 1995-2006, the CD rates continued to increase with an APC of 7.8\% (95\% Cl: 4.8, 10.9\%). After 2006, the CD rates started to decline by an APC of $-4.1 \%$ (95\% Cl: $-5.5,-2.6 \%)$. The CD rates non-significantly increased from 36.2\% in 2016 to 43.2\% in 2019. Moreover, the highest CD rate during 20152019 was observed on August 30 (59.2\%) and the lowest on September 1 (29.7\%). Primipara of older age and those with $>3$ pregnancies had higher risks of CD. Furthermore, primipara who gave birth to newborns with low birth weight and macrosomia had higher risks of CD.
\end{abstract}

Conclusions: Maternal and fetal as well as social and cultural factors may contribute to the rising trend of CD rates. Effective measures should be taken to control CD under the two-child policy, especially for primipara.

Keywords: Primipara, Cesarean delivery, Annual percentage change, Average annual percentage changes, Child policy

\section{Background}

Cesarean section is an effective way to improve the survival of mothers and newborns. However, the rapid increase in cesarean delivery (CD) adoption has not completely led a corresponding decrease in maternal and neonatal mortality. It has been suggested that the ideal $C D$ rate to reduce maternal and neonatal mortality is approximately $19 \%$ [1]. In the past 25 years, the rising

\footnotetext{
* Correspondence: chengyao2014@sina.com

Obstetrics Department, Maternal and Child Health Hospital of Hubei Province, Tongji Medical College, Huazhong University of Science and Technology, Wuluo Road 745\#, Hongshan District, Wuhan 430070, Hubei, China
}

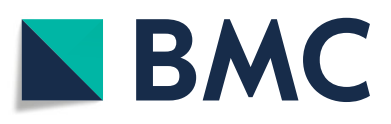

(c) The Author(s). 2020 Open Access This article is licensed under a Creative Commons Attribution 4.0 International License, which permits use, sharing, adaptation, distribution and reproduction in any medium or format, as long as you give appropriate credit to the original author(s) and the source, provide a link to the Creative Commons licence, and indicate if changes were made. The images or other third party material in this article are included in the article's Creative Commons licence, unless indicated otherwise in a credit line to the material. If material is not included in the article's Creative Commons licence and your intended use is not permitted by statutory regulation or exceeds the permitted use, you will need to obtain permission directly from the copyright holder. To view a copy of this licence, visit http://creativecommons.org/licenses/by/4.0/ The Creative Commons Public Domain Dedication waiver (http://creativecommons.org/publicdomain/zero/1.0/) applies to the data made available in this article, unless otherwise stated in a credit line to the data. trend in $\mathrm{CD}$ rates has been observed worldwide. Recently, an increase in $\mathrm{CD}$ rates from $6.4 \%$ in 2010 to $14.4 \%$ in 2016 was observed in low- and middle-income countries [2]. It has been reported that the CD rate in China was $36.7 \%$ in 2018, one of the highest in the world [3].

Since the implementation of the family planning onechild policy in the 1980s, families having an 'only-child' have increased in number in the mainland China [4]. The two-child policy was proposed since 2007 and officially implemented in 2013. With the full liberalisation of the two-child policy at the end of 2015, the 
proportion of elderly multiparous women with a previous CD largely increased [5]. CD could result in poor elasticity of the uterus, which might lead to uterine rupture and postpartum hemorrhage. Most pregnant mothers with a scarred uterus are obliged to undergo a secondary $\mathrm{CD}$. In addition, multiparous women with advanced maternal age and chronic diseases during pregnancy might also have a higher risk of $\mathrm{CD}$ [6]. It is difficult to reduce the $\mathrm{CD}$ rate among multipara in a short time. Therefore, in strategies for $\mathrm{CD}$ control, the focus should be on primipara. In China, the preference for $\mathrm{CD}$ among pregnant women or their families could have a large effect on the adoption of CD [7]. Maternal $\mathrm{CD}$ preference might be affected by traditional customs of a lucking day, children's education, or other social factors [8]. Moreover, cultural factors are changing along with social development. Therefore, the trends in CD rates during such social transitions could not only highlight the progress and challenges in $\mathrm{CD}$ control, but also reflect the influence of social development on $\mathrm{CD}$ to a certain extent. This study aimed to explore the trends in CD rates among primipara during 1995-2019 in China and the factors associated with CD risk.

\section{Methods}

\section{Data sources and study population}

The participants included in the study were women who delivered their babies at the Maternal and Child Health Care Hospital of Hubei Province, which is the largest tertiary maternity and child healthcare centre in Hubei Province. In 2018, 22.6\% of newborns in Wuhan were delivered at this hospital [9]. This retrospective study obtained clinical data of primiparous mothers (age at birth $\geq 16$ years and gestational age $\geq 28$ weeks) and newborns (fetal weight $\geq 1000 \mathrm{~g}$ ) from January 1, 1995 to December 31, 2019. GDP per capita at childbirth year was obtained from the Wuhan Provincial Bureau of Statistics [10]. This study was approved by the Ethics Committee of Maternal and Child Health Hospital of Hubei Province.

\section{Variable definitions}

Our dependent variable was the mode of delivery (vaginal delivery [VD] vs. CD). The independent variables related to maternal characteristics included the year of delivery; season of delivery (spring [March to May], summer [June to August], autumn [September to November], and winter [December to February]); maternal age at delivery $(<20,20-24,25-29,30-34$, and $>34$ years); gestational age at delivery (pre-term delivery $[<$ 37 weeks], term delivery [37-41 weeks], and post-term delivery [ $>41$ weeks]); gravidity $(1,2-3$, and $>3)$; fetus number (singleton and multiparous); and maternal complications [11]. Additionally, the independent variables related to neonatal characteristics included fetal position (head, breech, other, and unclassified); fetal sex (male, female, and unclassified); and weight at birth $(<1500 \mathrm{~g}$, $1500-2499$ g, 2500-3999 g, 4000-4499 g, and $>4499$ g).

\section{Data analysis}

Chi-square tests were used to evaluate the differences in the primary variables including maternal and neonatal characteristics between VD and CD. Multiple logistic regression analyses were used to evaluate the effects of maternal and neonatal factors on the type of delivery. Potential confounding variables, including gestational week, complications, fetal position, and GDP per capita at childbirth year, were adjusted for. Results of multiple log-binomial regression analyses are reported as adjusted odds ratios (ORs) and corresponding 95\% confidence intervals (CIs). All tests were two-sided, and $p$ values < 0.05 were considered statistically significant. Statistical analyses were performed using SAS 9.4 for Windows.

Trends in CD rates were calculated using the joinpoint regression analysis proposed by Kim et al. (Joinpoint Regression Software, Version 4.0.4-May 2013; Statistical Methodology and Applications Branch, Surveillance Research Program of the US National Cancer Institute) [12]. The annual percentage change (APC) and the average annual percentage change (AAPC) with the corresponding 95\% CI were further estimated.

\section{Results}

A total of 177,668 primiparous women were included in this study, of which 175,342 had singleton pregnancies and 2326 had multiparous pregnancies. Table 1 shows the demographic characteristics of nulliparous women, and Table S1 shows the demographic characteristics of all mothers. There were significant differences in demographic characteristics between women undergoing VD and $\mathrm{CD}$. The proportion of VD was higher than that of CD among primipara in $2015-2019$ (43.3\% vs. $37.1 \%$, $p<0.0001)$. Additionally, more than half of all primiparous women included in this study were aged 25-29 years (60.3\%). The proportion of $\mathrm{CD}$ among primiparous women aged $30-34$ years or $>34$ years was significantly higher than that of VD ( $27.3 \%$ vs. $18.8 \% ; 5.3 \%$ vs. $1.2 \%$, $p<0.0001)$. The proportion of VD was higher than that of $\mathrm{CD}$ among primipara when the GDP per capita was over $¥ 90,000$ ( $25.3 \%$ vs. $20.9 \%$; $25.9 \%$ vs. $23.9 \%, p<$ $0.0001)$. Furthermore, the proportion of pre-term birth among those who underwent $\mathrm{CD}$ was higher than that among those who underwent VD (8.9\% vs. $5.6 \%, p<$ 0.0001 ). The proportion of primiparous women in the first pregnancy accounted for $64.1 \%$ of the sample, and primiparous women with more than one pregnancy underwent $\mathrm{CD}$ more frequently than they did VD. Additionally, multiparous women reported a higher 
Table 1 Characteristics of primipara between 1995 and 2019

\begin{tabular}{|c|c|c|c|c|}
\hline Variables & VD & $C D$ & Total & $P$-value \\
\hline \multicolumn{5}{|l|}{ Maternal } \\
\hline Year & & & & $<0.0001$ \\
\hline 1995-1999 & $6725(6.9)$ & $2825(3.5)$ & $9550(5.4)$ & \\
\hline $2000-2004$ & $6525(6.7)$ & $5165(6.5)$ & $11,690(6.6)$ & \\
\hline 2005-2009 & $13,266(13.6)$ & $15,933(19.9)$ & 29,199 (16.4) & \\
\hline 2010-2014 & $28,931(29.6)$ & $26,324(32.9)$ & $55,255(31.1)$ & \\
\hline 2015-2019 & $42,315(43.3)$ & $29,659(37.1)$ & $71,974(40.5)$ & \\
\hline Season & & & & $<0.0001$ \\
\hline Spring & $23,396(23.9)$ & $19,993(25.0)$ & $43,389(24.4)$ & \\
\hline Summer & $25,272(25.9)$ & $20,525(25.7)$ & $45,797(25.8)$ & \\
\hline Autumn & $25,774(26.4)$ & $20,283(25.4)$ & $46,057(25.9)$ & \\
\hline Winter & $23,320(23.9)$ & $19,105(23.9)$ & $42,425(23.9)$ & \\
\hline Age (years) & & & & $<0.0001$ \\
\hline$<20$ & $429(0.4)$ & $187(0.2)$ & $616(0.4)$ & \\
\hline $20-24$ & $15,747(16.1)$ & 8587 (10.8) & $24,334(13.7)$ & \\
\hline $25-29$ & $61,980(63.4)$ & $45,060(56.4)$ & $107,040(60.3)$ & \\
\hline $30-34$ & $18,398(18.8)$ & $21,831(27.3)$ & $40,229(22.6)$ & \\
\hline$>34$ & $1208(1.2)$ & $4241(5.3)$ & $5449(3.1)$ & \\
\hline GDP per capita ( $¥)$ & & & & $<0.0001$ \\
\hline$<30,000$ & $14,976(15.3)$ & $9896(12.4)$ & $24,872(14.0)$ & \\
\hline $30,000-60,000$ & $15,781(16.1)$ & $19,079(23.9)$ & 34,860 (19.6) & \\
\hline $60,000-90,000$ & $16,924(17.3)$ & $15,111(18.9)$ & $32,035(18.0)$ & \\
\hline $90,000-120,000$ & $24,722(25.3)$ & $16,735(20.9)$ & $41,457(23.3)$ & \\
\hline$>120,000$ & $25,359(25.9)$ & $19,085(23.9)$ & $44,444(25.0)$ & \\
\hline Gestational age (weeks) & & & & $<0.0001$ \\
\hline$<37$ & $5455(5.6)$ & $7146(8.9)$ & $12,601(7.1)$ & \\
\hline $37-41$ & $91,826(93.9)$ & $72,296(90.5)$ & $164,122(92.4)$ & \\
\hline$>41$ & $481(0.5)$ & $464(0.6)$ & $945(0.5)$ & \\
\hline Gravidity & & & & $<0.0001$ \\
\hline 1 & $65,608(67.1)$ & $48,327(60.5)$ & $113,935(64.1)$ & \\
\hline $2-3$ & $29,936(30.6)$ & $28,185(35.3)$ & $58,121(32.7)$ & \\
\hline$>3$ & $2218(2.3)$ & $3394(4.3)$ & $5612(3.2)$ & \\
\hline Fetus number & & & & $<0.0001$ \\
\hline Singleton & $97,588(99.8)$ & $77,754(97.3)$ & $175,342(98.7)$ & \\
\hline Multiparous & $174(0.2)$ & $2152(2.7)$ & $2326(1.3)$ & \\
\hline Complications & & & & $<0.0001$ \\
\hline Yes & $21,355(21.8)$ & $36,803(46.1)$ & $58,158(32.7)$ & \\
\hline No/Unclassified & $76,407(78.2)$ & $43,103(53.9)$ & $119,510(67.3)$ & \\
\hline \multicolumn{5}{|l|}{ Neonatal } \\
\hline Position & & & & $<0.0001$ \\
\hline Head & $97,075(99.5)$ & $69,374(89.2)$ & $166,449(94.9)$ & \\
\hline Breech & $202(0.2)$ & $7723(9.9)$ & $7925(4.5)$ & \\
\hline Other & $21(0)$ & $226(0.3)$ & $247(0.1)$ & \\
\hline Unclassified & $290(0.3)$ & $431(0.6)$ & $721(0.4)$ & \\
\hline
\end{tabular}


Table 1 Characteristics of primipara between 1995 and 2019 (Continued)

\begin{tabular}{llll}
\hline Variables & VD & CD & Total \\
\hline Sex & & & \multicolumn{1}{c}{$<$-value } \\
Male & $49,846(51.1)$ & $41,537(53.4)$ & $91,383(52.1)$ \\
Female & $47,730(48.9)$ & $36,212(46.6)$ & $83,942(47.9)$ \\
Unclassified & $12(0)$ & $5(0)$ & $17(0)$ \\
Weight (g) & & $260(0.3)$ & $587(0.3)$ \\
$1000-1500$ & $327(0.3)$ & $3910(5.0)$ & $7083(4.0)$ \\
$1500-2499$ & $3173(3.3)$ & $65,328(84.0)$ & $156,178(89.1)$ \\
$2500-3999$ & $90,850(93.1)$ & $7290(9.4)$ & $10,406(5.9)$ \\
$4000-4499$ & $3116(3.2)$ & $966(1.2)$ & $1088(0.6)$ \\
$>4499$ & $122(0.1)$ &
\end{tabular}

Abbreviations: VD Vaginal delivery, $C D$ Cesarean delivery

proportion of $\mathrm{CD}$ than that of $\mathrm{VD}(2.7 \%$ vs. $0.2 \%, p<$ $0.0001)$. Primiparous women with maternal complications also had a higher proportion of CD (46.1\% vs. $21.8 \%, p<0.0001)$.

For singleton neonates, the head position was the most common (94.9\%) (Table 1). Among neonates in the head position, the proportion of VD was higher than that of CD (99.5\% vs. $89.2 \%, p<0.0001)$. Male newborns had a slightly higher rate of CD than that of VD $(53.4 \%$ vs. $51.1 \%, p<0.0001)$. In addition, newborns with macrosomia also had higher rates of CD (9.4\% vs. $3.2 \%$; $1.2 \%$ vs. $0.1 \%, p<0.0001)$.

Figure 1 and Table S2 present the trends among CD rates of primiparous women during 1995-2019. The CD rates showed a significant upward trend during the study period (AAPC: 2.2, 95\% CI: 0.6, 3.8\%). In 1995-2006, the $\mathrm{CD}$ rates continued to increase from 19.1 to $60.5 \%$ with an APC of 7.8\% (95\% CI: 4.8, 10.9\%). After 2006, the CD rates started to decline by an APC of $-4.1 \%$ (95\% CI: $-5.5,-2.6 \%)$. The second inflexion point occurred in 2016. The CD rates showed a non-significant increase from $36.2 \%$ in 2016 to $43.2 \%$ in 2019 (APC: 3.5 , 95\% CI: $-3.7,11.3 \%)$.

Figure 2 shows the daily average CD rates among primiparous women during different study periods. In total, the highest $C D$ rate during 1995-2019 was observed on August 28 (57.3\%) and the lowest on May 1 (38.7\%). With respect to 5-year periods, during 1995-1999, 2000-2004, 2005-2009, 2010-2014, and 2015-2019, the highest CD rates were observed on on June $2(56.5 \%)$, October $9(66.7 \%)$, August 18 (76.7\%), June 9 (64.9\%), and August 30 (59.24\%), respectively. In contrast, the lowest rate was observed on October 3 (6.9\%), May 27 (20.0\%), July 16 (37.4\%), October 27 (37.4\%), September 1 (29.7\%), respectively.

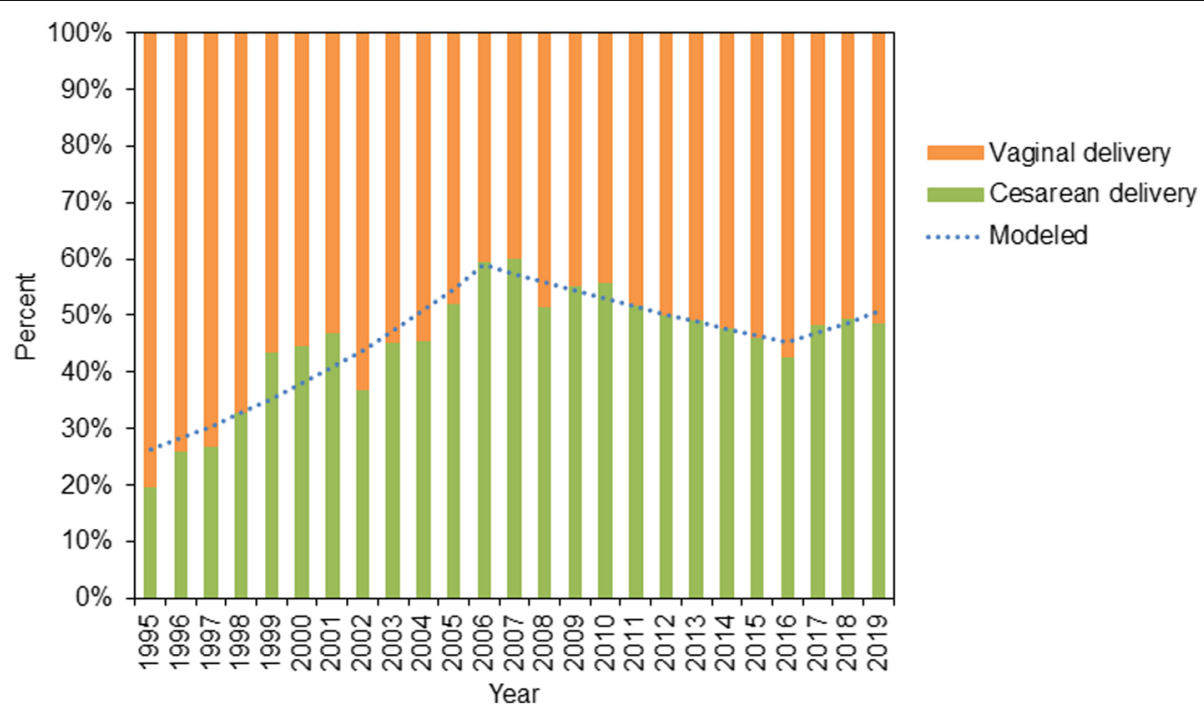

Fig. 1 Trends in cesarean delivery rates among primipara during 1995-2019 

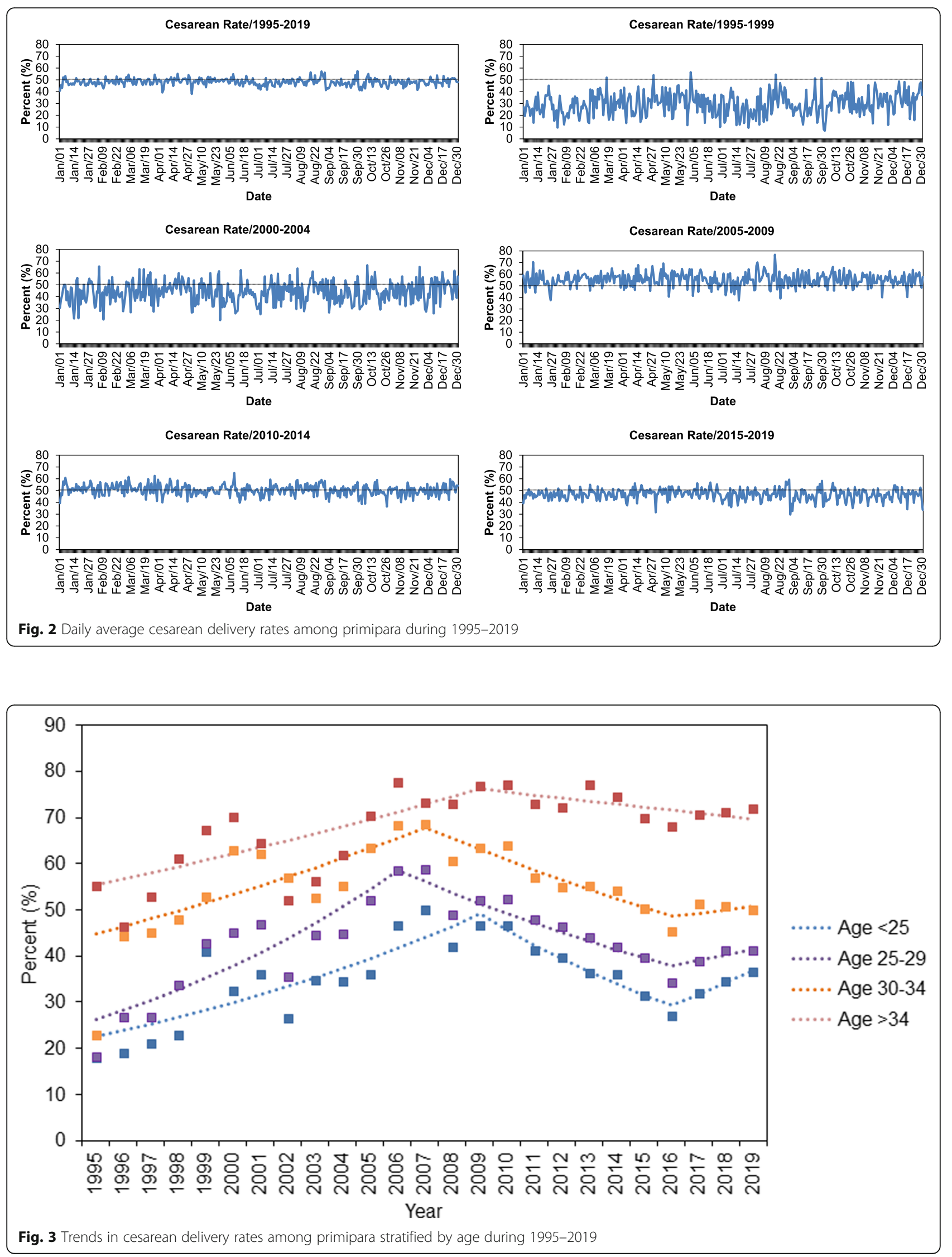
Figure 3 and Table S2 demonstrate the trends in CD rates among primiparous women stratified by age group. Trends in CD rates among primiparous women aged < 25 years showed a significant increase during 1995-2009 (APC: 5.5, 95\% CI: 3.2, 7.9\%), and then a decrease in 2009-2016 (APC: -7.9, 95\% CI: - 12.0, - 3.5\%). CD rates among primiparous women aged 25-29 years showed similar trends; they increased with an APC of 7.6\% (95\% CI: 4.4, 10.8\%) in 1995-2006 and decreased with an APC of $-4.9 \%$ (95\% CI: $-6.5,-3.3 \%$ ) in 2006-2016, and then non-significant increases since 2016. CD rates among primiparous women aged 30-34 years and $>34$ years showed increasing trends with APC of 3.5\% (95\% CI: $1.3,5.8 \%$ ) and $2.8 \%$ (95\% CI: $1.0,4.5 \%$ ), respectively, followed by decreases in 2007-2019 (APC: -3.6, 95\% CI: $-4.9,-2.4 \%$ ) and 2005-2019 (APC: -1.4, 95\% CI: - 1.7, $-1.1 \%)$, respectively.

Figure 4 and Table S2 present the trends in CD rates among primiparous women with singleton pregnancies stratified by fetal weight. CD rates among newborns with normal weight demonstrated an upward trend with an APC of $8.6 \%$ (95\% CI: 5.3, 12.1\%) in 1995-2006, and then significantly decreased in 2006-2016 (APC: -4.7, 95\% CI: $-6.3,-3.1 \%)$. The trends in CD rates among low-birth-weight newborns increased in 1995-2010 (APC: 5.1, 95\% CI: 3.1, 7.2\%). After 2016, this trend showed a steeper increase (APC: 14.8, 95\% CI: 8.4, 21.7\%). Furthermore, the $\mathrm{CD}$ rates among those with macrosomia increased in 1995-2000 (APC: 11.3, 95\%
CI: $1.6,22.0 \%)$ and then slightly decreased in 2000-2019 (APC: $-0.9,95 \%$ CI: $-1.4,-0.3 \%$ ). Results of multiple sensitivity analysis of trends in CD rates during 20052019 are presented in Table S4-S5.

The associations of maternal and neonatal factors with $\mathrm{CD}$ among singleton primiparous women are shown in Table 2. Compared with women aged 20-24 years, those with older maternal age $(25-29,30-34$, and $>34$ years) showed a higher risk of $\mathrm{CD}$ in the adjusted model (OR: 1.2, 95\% CI: 1.1, 1.3; OR: 1.5, 95\% CI: 1.4, 1.6; OR: 1.9 , 95\% CI: 1.7, 2.2, respectively). Compared with primiparous women with a single pregnancy, those with $2-3$ times or $>3$ pregnancies had a significantly higher risk of CD (OR: 1.1, 95\% CI: 1.0, 1.1; OR: 1.2, 95\% CI: 1.1, 1.4, respectively). Furthermore, women giving birth to newborns with low birth weight have a higher risk of CD (OR: 1.2, 95\% CI: 1.0, 1.3) and those who gave birth to newborns with macrosomia also showed higher risks of CD (OR: 1.6, 95\% CI: 1.5, 1.8; OR: 2.3, 95\% CI: 1.7, 3.2 , respectively).

\section{Discussion}

This study reported the trends in CD rates among primiparous women in the past 25 years under the one-child and the two-child policies in China. Overall, the $C D$ rate among primipara in China is much higher than the global average [13]. We found that the $\mathrm{CD}$ rates significantly increased from $19.1 \%$ in 1995 to $43.2 \%$ in 2019 , consistent with a previous study conducted among

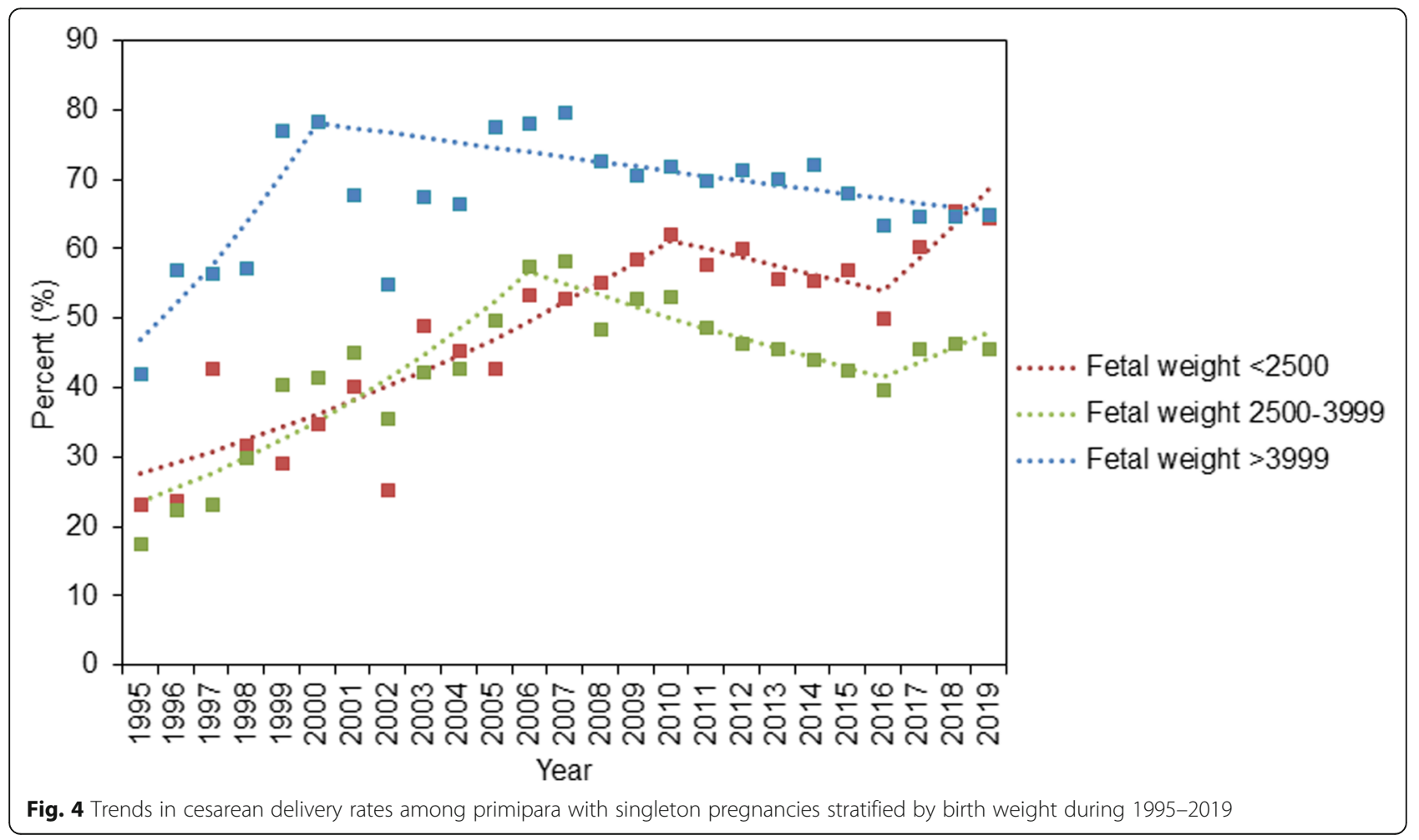


Table 2 Associations of maternal and neonatal factors with cesarean delivery among primipara with singleton pregnancies

\begin{tabular}{|c|c|c|}
\hline Variables & Unadjusted OR (95\% Cl) & Adjusted OR $(95 \% \mathrm{Cl})$ \\
\hline \multicolumn{3}{|l|}{ Maternal } \\
\hline \multicolumn{3}{|l|}{ Age (years) } \\
\hline$<20$ & $0.7(0.6,1.0)$ & $0.8(0.5,1.2)$ \\
\hline $20-24$ & Ref & Ref \\
\hline $25-29$ & $1.2(1.2,1.3)$ & $1.2(1.1,1.3)$ \\
\hline $30-34$ & $1.7(1.6,1.7)$ & $1.5(1.4,1.6)$ \\
\hline$>34$ & $2.6(2.4,2.7)$ & $1.9(1.7,2.2)$ \\
\hline \multicolumn{3}{|l|}{ Gravidity } \\
\hline 1 & Ref & Ref \\
\hline $2-3$ & $1.1(1.1,1.2)$ & $1.1(1.0,1.1)$ \\
\hline$>3$ & $1.2(1.1,1.3)$ & $1.2(1.1,1.4)$ \\
\hline \multicolumn{3}{|l|}{ Year } \\
\hline 1995-1999 & Ref & Ref \\
\hline $2000-2004$ & $1.5(1.4,1.6)$ & $1.4(1.2,1.6)$ \\
\hline 2005-2009 & $1.9(1.8,2.0)$ & $1.3(1.1,1.6)$ \\
\hline 2010-2014 & $1.6(1.5,1.7)$ & $1.3(1.0,1.6)$ \\
\hline 2015-2019 & $1.3(1.3,1.4)$ & $1.1(0.9,1.4)$ \\
\hline \multicolumn{3}{|l|}{ Season } \\
\hline Spring & Ref & Ref \\
\hline Summer & $1.0(0.9,1.0)$ & $1.0(0.9,1.1)$ \\
\hline Autumn & $1.0(0.9,1.0)$ & $1.0(0.9,1.0)$ \\
\hline Winter & $1.0(0.9,1.0)$ & $1.0(0.9,1.0)$ \\
\hline \multicolumn{3}{|l|}{ Neonatal } \\
\hline \multicolumn{3}{|l|}{ Sex } \\
\hline Male & $1.0(1.0,1.1)$ & $1.0(1.0,1.1)$ \\
\hline Female & Ref & Ref \\
\hline \multicolumn{3}{|l|}{ Weight (g) } \\
\hline$<1500$ & $1.0(0.9,1.3)$ & $0.9(0.6,1.3)$ \\
\hline $1500-2499$ & $1.4(1.3,1.4)$ & $1.2(1.0,1.3)$ \\
\hline 2500-3999 & Ref & Ref \\
\hline 4000-4499 & $1.9(1.8,2.0)$ & $1.6(1.5,1.8)$ \\
\hline$>4499$ & $1.9(1.8,2.1)$ & $2.3(1.7,3.2)$ \\
\hline
\end{tabular}

Adjusted for gestational age, complications, fetal position, and GDP per capita at childbirth year; Bold values represent statistical significance (two-sided $p<0.05$ )

primiparous women from 1993 to 2003 [14]. Furthermore, we found that the $\mathrm{CD}$ rates among primipara showed a significant rapid rising trend with an APC of $7.8 \%$ during 1995-2006, likely owing to the socioeconomic development in China.

The $\mathrm{CD}$ rates among primipara declined significantly from 2006 to 2016. A study conducted by Liao et al. also reported that the $\mathrm{CD}$ rates in Hubei Province decreased significantly from 2013 to 2016 [15], and Liu et al. confirmed that the $\mathrm{CD}$ rates among primipara with singleton cephalic term pregnancy reduced significantly from $29.3 \%$ in 2011 to $16.4 \%$ in 2016 [16]. The difference in CD rates between 1995 and 2006 and 20062016 are mainly due to the obstetricians' awareness of $\mathrm{CD}$ control and pregnant women's demands for $\mathrm{CD}$ [17].

The elevated risk of maternal and neonatal mortality owing to the high rate of $C D$ had warned health management authorities regarding the need for CD control. In 2001, the sketch of China's women development (2001-2010), issued by the Health and Family Planning Commission, announced their mission to 'Reduce unnecessary medical intervention of $C D$ to improve the quality of obstetrics'. After the national policy of $\mathrm{CD}$ control was put forward in 2001, it took a few years to formulate and implement effective control measures in various medical institutions. The declining trend during 2006-2016 might be partly explained by the effect of CD control policies [18]. Hospital interventions, including health education for pregnant women and obstetricians on the advantages of VD and the disadvantages of unnecessary $\mathrm{CD}$, might have contributed to the decreasing $\mathrm{CD}$ rates [19-21]. Moreover, the introduction of painless delivery and doula care also helped reduce the $C D$ rate [22]. CD control is regarded as health care quality management in obstetric department of the Maternal and Child Health Hospital of Hubei Province, and the use of $\mathrm{CD}$ without medical indication was strictly controlled since 2006.

However, this study showed that after the implementation of the two-child policy, the $\mathrm{CD}$ rates stopped decreasing after 2016. Researchers have suggested that the increasing trend of $\mathrm{CD}$ rates after the implementation of the two-child policy was mainly attributed to the increased proportion of women with previous CD [23]. However, the use of $\mathrm{CD}$ among primiparous women under the two-child policy should be taken into consideration.

Interestingly, the highest average daily $\mathrm{CD}$ rate in 1995-2019 was observed on August 28, and it changed from June 2 in 1995-1999 to August 30 in 2015-2019. This observation indicates that pregnant women or their families might be likely to choose a good day for CD [8]. Furthermore, the lowest CD rate was observed on September 1 in 2015-2019, consistent with the timing of school reopening in China, which might indicate that many parents use CD instead of VD to prepone the delivery date in order to get their children into school earlier. This conception was particularly obvious in recent years with the rapid socio-economic development of China. It was a great challenge for health managers to control the CD rate caused by social factors [22].

Previous studies have indicated that most women who plan to have a second child were prone to choosing VD 
for the first child under the two-child policy [8, 24]. Wang et al. conducted in-depth interviews with 45 women, which indicated that most participants were hesitant to have a second child [25]. In this study, the highest proportion of primiparas comprised mothers aged $25-29$ years $(52.0 \%)$. The CD rates in mothers aged $<34$ years decreased significantly but showed an inflexion point of increase in 2016. The CD rates among primipara in these age groups did not decrease continuously, which might have been related to the decreased demand of a second child under the two-child policy [26].

Regarding the influence of neonatal characteristics on the risk of $C D$, this study showed a rapid increase in $C D$ rates in newborns with low birth weight, confirming results from previous studies [27]. Song et al. reported that neonates of low birth weight had a 2-fold higher risk of CD than neonates of normal weight [28], and another study conducted in Taiwan demonstrated an elevated risk of parent-requested CD [29]. For some mothers with pregnancy complications, the use of $\mathrm{CD}$ could improve the birth outcome of both mothers and newborns [30]. The increase in the number of primiparous women with advanced age or pregnancy complications might partly explain the rising trend of $C D$ rates among newborns with low birth weight [31]. Moreover, the rapid rising trends in the proportion of newborns with low birth weight might also be attributed to the increased CD rates (Table S3).

This study showed that advanced maternal age at childbirth was positively associated with $\mathrm{CD}$. Mothers with advanced age at childbirth have a higher risk of a wide range of adverse maternal outcomes and neonatal mortality, associated with a more frequent adoption of CD [32-34]. Moreover, mothers with previous miscarriages or abortions have a higher risk of subsequent miscarriage and stillbirth. Consistent with previous studies, the present study also showed an elevated risk of $C D$ among primiparous women with previous miscarriage or abortion history $[35,36]$.

This study, in line with previous studies, fetal macrosomia was also associated with an elevated risk of $C D$, which might partly be explained by the elevated risk of stillbirth and birth canal injury during VD in cases of fetal macrosomia [37, 38]. Additionally, the proportion of macrosomia decreased significantly during the whole study period, and the proportion of macrosomia showed a steeper downwards trend during 2016-2019 (Table S3), which might be helpful in long-term CD control.

This study evaluated the progress and challenges of $\mathrm{CD}$ control during the social transition in China. However, this study also has some limitations. First, it was based on data from one hospital, and the generalizability of the results to other regions is limited. Second, the data from early years used in this study were registered manually, which may have led to mistakes and omissions. Third, the individual economic and social factors influencing $C D$ rates were not investigated in-depth; therefore, factors influencing CD rates warrant further study. Finally, other fetal factors, including cord around the neck, fetal distress, and asphyxia et al., which are important CD indicators, were excluded from this study, as these data were missing in prior years.

\section{Conclusions}

The overall CD rates among primiparous women increased during 1995-2019. However, the trends in CD rates significantly decreased during the one-child policy period, which might indicate that $C D$ adoption was effectively controlled. However, the CD rates did not continue to decline once the two-child policy was implemented. It has been suggested that interventions including health education, promotion of painless delivery, and doula care could be helpful for CD control. Additionally, social and cultural factors may also contribute to the rising trend in $\mathrm{CD}$ rates, which needs to be studied further. The results of this study also suggest that reducing the age at delivery among primipara and controlling fetal macrosomia could decrease the risk of CD.

\section{Supplementary Information}

The online version contains supplementary material available at https://doi. org/10.1186/s12884-020-03398-6.

Additional file 1: Table S1. Characteristics of maternal mothers between 1995 and 2019. Table S2. Joinpoint regression analysis of trends in cesarean delivery rates stratified by age and fetal weight during 1995-2019. Table S3. Joinpoint regression analysis of trends in the proportion of fetal weight during 1995-2019. Table S4. Joinpoint regression analysis of trends in cesarean delivery rates stratified by age and fetal weight during 2005-2019. Table S5. Joinpoint regression analysis of trends in the proportion of fetal weight during 2005-2019.

\section{Abbreviations \\ AAPC: Average annual percentage change; APC: Annual percentage change; CD: Cesarean delivery; Cl: Confidence interval; OR: Odds ratio; VD: Vaginal delivery}

\section{Acknowledgements}

We would like to thank the medical staff of the Maternal and Child Health Hospital of Hubei Province for their contributions towards CD control.

\section{Authors' contributions}

GS conceived, designed and performed the experiments. $Y \mathrm{~L}, \mathrm{HL}$, and $\mathrm{WH}$ performed data interpretation, visualization, and reviewed the manuscript. $R L, L Y, X L, H W$, and $X Y$ performed data interpretation, reviewed and revised the manuscript. $Y C$ performed the experiments, analysed the data, and wrote the paper. All authors have read and agreed to publish the final manuscript. 


\section{Availability of data and materials}

Data for this study are available upon reasonable request from the corresponding author with permission from the Ethics Committee of Maternal and Child Health Hospital of Hubei Province.

\section{Ethics approval and consent to participate}

This study was approved by the Ethics Committee of Maternal and Child Health Hospital of Hubei Province and this study was based on the retrospective clinical data without any individual patient identifiers.

\section{Consent for publication}

Not applicable.

\section{Competing interests}

The authors declare no potential conflict of interests.

Received: 8 July 2020 Accepted: 5 November 2020

Published online: 23 November 2020

\section{References}

1. Molina G, Weiser TG, Lipsitz SR, Esquivel MM, Uribe-Leitz T, Azad T, et al. Relationship between cesarean delivery rate and maternal and neonatal mortality. JAMA. 2015;314:2263-70.

2. Harrison MS, Saleem S, Ali S, Pasha O, Chomba E, Carlo WA, et al. A prospective, population-based study of trends in operative vaginal delivery compared to cesarean delivery rates in low- and middle-income countries, 2010-2016. Am J Perinatol. 2019;36:730-6.

3. Li HT, Hellerstein S, Zhou YB, Liu JM, Blustein J. Trends in cesarean delivery rates in China, 2008-2018. JAMA. 2020;323:89-91.

4. Gietel-Basten S, Han X, Cheng Y. Assessing the impact of the "one-child policy" in China: a synthetic control approach. PLoS One. 2019;14:e0220170.

5. Liu Y, Qin Q, Xiao Y, Li H, Guang S, Tao S, et al. Changes of second-time mothers and their infants under the universal two-child policy in Changsha, China. Midwifery. 2019;77:32-6.

6. Xie M, Lao TT, Du M, Sun Q, Qu Z, Ma J, et al. Risk for cesarean section in women of advanced maternal age under the changed reproductive policy in China: a cohort study in a tertiary hospital in southwestern China. J Obstet Gynaecol Res. 2019;45:1866-75.

7. Long Q, Kingdon C, Yang F, Renecle MD, Jahanfar S, Bohren MA, et al. Prevalence of and reasons for women's, family members', and health professionals' preferences for cesarean section in China: a mixed-methods systematic review. PLoS Med. 2018;15:e1002672.

8. Liang H, Fan Y, Zhang N, Chongsuvivatwong V, Wang Q, Gong J, et al. Women's cesarean section preferences and influencing factors in relation to China's two-child policy: a cross-sectional study. Patient Prefer Adherence. 2018;12:2093-101.

9. Wuhan Bureau of Statistics. Wuhan National Economic and social development statistical bulletin in 2018; 2019. (in Chinese). http:// tjjwuhangoven/detailsaspx?id=4368. Accessed 19 Mar 2020

10. Wuhan Bureau of Statistics. Wuhan statistical yearbook (1995-2019). (in Chinese). http://tjj.wuhan.gov.cn/tjfw/tjnj/. Accessed 1 Oct 2020.

11. Liang J, Mu Y, Li X, Tang W, Wang Y, Liu Z, et al. Relaxation of the one child policy and trends in caesarean section rates and birth outcomes in China between 2012 and 2016: observational study of nearly seven million health facility births. BMJ. 2018;360:k817.

12. Kim J, Kim HJ. Consistent model selection in segmented line regression. J Stat Plan Inference. 2016:170:106-16.

13. Boerma T, Ronsmans C, Melesse DY, Barros AJD, Barros FC, Juan L, et al. Global epidemiology of use of and disparities in caesarean sections. Lancet. 2018;392:1341-8.

14. Tang S, Li X, Wu Z. Rising cesarean delivery rate in primiparous women in urban China: evidence from three nationwide household health surveys. Am J Obstet Gynecol. 2006;195:1527-32

15. Liao Z, Zhou Y, Li H, Wang C, Chen D, Liu J. The rates and medical necessity of cesarean delivery in the era of the two-child policy in Hubei and Gansu provinces, China. Am J Public Health. 2019;109:476-82.

16. Liu $X$, Huang D, Landon MB, Cheng W, Chen Y. Trends in cesarean delivery rate after cessation of the one-child policy in China. Am J Perinatol. 2020. https://doi.org/10.1055/s-0040-1705176.
17. Sun N, Yin X, Qiu L, Yang Q, Gong Y. Chinese obstetricians' attitudes, beliefs, and clinical practices related to cesarean delivery on maternal request. Women Birth. 2020;33:e67-71.

18. Li HT, Luo S, Trasande L, Hellerstein S, Kang C, Li JX, et al. Geographic variations and temporal trends in cesarean delivery rates in China, 20082014. JAMA. 2017;317:69-76.

19. Gao Y, Tang Y, Tong M, Du Y, Chen Q. Does attendance of a prenatal education course reduce rates of caesarean section on maternal request? A questionnaire study in a tertiary women hospital in Shanghai. China BMJ Open. 2019;9:e029437.

20. Harris A, Gao Y, Barclay L, Belton S, Yue ZW, Min H, et al. Consequences of birth policies and practices in post-reform China. Reprod Health Matt. 2007; 15:114-24.

21. Sun GQ, Yang $H$, Zhang $H$, Tan $Z$ H. Effect of propaganda and education of knowledge about "how to choose delivery modes" in pregnancy school on cesarean section rate. Matern Child Health Care China. 2013;28:5114-7 (In Chinese).

22. Yu Y, Zhang X, Sun C, Zhou H, Zhang Q, Chen C. Reducing the rate of cesarean delivery on maternal request through institutional and policy interventions in Wenzhou, China. PLoS One. 2017;12:e0186304.

23. Zhang Y, Gu N, Wang Z, Zheng M, Hu Y, Dai Y. Use of the 10-group classification system to analyze how the population control policy change in China has affected cesarean delivery. Int J Gynaecol Obstet. 2017;138: 158-63.

24. Zhao J, Shan N, Yang X, Li Q, Xia Y, Zhang H, et al. Effect of second child intent on delivery mode after Chinese two child policy implementation: a cross sectional and prospective observational study of nulliparous women in Chongqing. BMJ Open. 2017;7:e018823.

25. Wang $E$, Hesketh $T$. Large reductions in cesarean delivery rates in China: a qualitative study on delivery decision-making in the era of the two-child policy. BMC Pregnancy Childbirth. 2017;17:405.

26. Wang E, Hesketh T. Exploring women's decisions about childbearing after the lifting of the one-child policy. Cult Health Sex. 2018;20:1230-43.

27. Blanc J, Resseguier N, Goffinet F, Lorthe E, Kayem G, Delorme P, et al. Association between gestational age and severe maternal morbidity and mortality of preterm cesarean delivery: a population-based cohort study. Am J Obstet Gynecol. 2019:220:399.e1-9.

28. Song G, Wei YM, Zhu WW, Yang HX. Cesarean section rate in singleton Primiparae and related factors in Beijing, China. Chin Med J. 2017;130:2395-401.

29. Liu TC, Chen CS, Tsai YW, Lin HC. Taiwan's high rate of cesarean births: impacts of national health insurance and fetal gender preference. Birth. 2007:34:115-22

30. Gao Y, Xue Q, Chen G, Stone P, Zhao M, Chen Q. An analysis of the indications for cesarean section in a teaching hospital in China. Eur J Obstet Gynecol Reprod Biol. 2013;170:414-8.

31. East CE, Biro MA, Fredericks S, Lau R. Support during pregnancy for women at increased risk of low birthweight babies. Cochrane Database Syst Rev. 2019;4:CD000198.

32. Leader J, Bajwa A, Lanes A, Hua X, Rennicks White R, Rybak N, et al. The effect of very advanced maternal age on maternal and neonatal outcomes: a systematic review. J Obstet Gynaecol Can. 2018;40:1208-18.

33. Castiglioni L, Schmiedeberg C. Joint effect of education and age at childbirth on the risk of caesarean delivery: findings from Germany 20082015. Public Health. 2018;155:1-7.

34. Tabcharoen C, Pinjaroen S, Suwanrath C, Krisanapan O. Pregnancy outcome after age 40 and risk of low birth weight. J Obstet Gynaecol. 2009;29:378-83.

35. Magnus MC, Wilcox AJ, Morken NH, Weinberg CR, Håberg SE. Role of maternal age and pregnancy history in risk of miscarriage: prospective register based study. BMJ. 2019:364:1869.

36. Giang HTN, Ulrich S, Tran HT, Bechtold-Dalla PS. Monitoring and interventions are needed to reduce the very high caesarean section rates in Vietnam. Acta Paediatr. 2018;107:2109-14.

37. Fuchs F, Bouyer J, Rozenberg P, Senat MV. Adverse maternal outcomes associated with fetal macrosomia: what are the risk factors beyond birthweight? BMC Pregnancy Childbirth. 2013;13:90.

38. Parkes I, Kabiri D, Hants Y, Ezra Y. The indication for induction of labor impacts the risk of cesarean delivery. J Matern Fetal Neonatal Med. 2016;29:224-8.

\section{Publisher's Note}

Springer Nature remains neutral with regard to jurisdictional claims in published maps and institutional affiliations. 